\title{
Minimum Acceptable Diet Practice and its Associated Factors among Children's Aged 6-23 Months in Rural Communities of Goncha District, North West Ethiopia, 2020
}

Mr Birie ( $\sim$ bamlakubirie21@gmail.com )

Mizan Tepi University

\section{Dr Kassa}

Hawassa University

Mrs Kebede

Hawassa University

\section{Research Article}

Keywords: minimum acceptable diet, 6-23 month children, Goncha district, Northwest Ethiopia.

Posted Date: December 17th, 2020

DOl: https://doi.org/10.21203/rs.3.rs-126420/v1

License: (c) (1) This work is licensed under a Creative Commons Attribution 4.0 International License. Read Full License

Version of Record: A version of this preprint was published at BMC Nutrition on July 20th, 2021. See the published version at https://doi.org/10.1186/s40795-021-00444-0. 


\section{Abstract}

Introduction: After the first 6 months breast milk is no longer sufficient to meet the nutritional needs of the infant. Therefore, complementary foods should be added to the child's diet. Feeding children's with diversified diet is practiced improperly in developing countries including Ethiopia particularly in the rural community. Interventions are intended to undertake the nutrition problems in children in the country. However, the progress was not satisfactory, particularly; minimum acceptable diet has increased from $3 \%$ to $7 \%$ in a decade (2005-2016).

Objective: To determine the proportion of minimum acceptable diet practice and its associated factors among children's aged 6-23 months in rural communities of Goncha district, 2020

Methodology: Community based cross-sectional study was employed at rural communities of Goncha district from June 15 to July 15 2020. Multi stage sampling technique was used to select study subjects, and interview administered structured questionnaire was used to collect the data. Data was entered by Epi Data version 4.0.2 and exported to SPSS 20 for analysis. Bivariate and multivariable logistic regression analysis was used to see the association between minimum acceptable diet and independent variable. Then, $\mathrm{P}$-value $<0.05$ with $95 \% \mathrm{Cl}$ on multivariable logistic regression analysis were used to identify the independent predictor of outcome variable

Result: A total of 430 mothers who have children aged 6-23 months were included in the analysis with $98 \%$ of response rate. About $12.6 \%$ of children's aged $6-23$ months received the recommended minimum acceptable diet. Children whose mothers who had formal education [AOR=2.7, 95\% Cl $(1.133,6.231)]$, institutional delivery $[A O R=4.5,95 \% \mathrm{Cl}(1.986,10.362)]$, media exposure $[A O R=2.6,95 \% \mathrm{Cl}(1.303,5.291)]$ and higher household wealth index $[A O R=2.5,95 \% \mathrm{Cl}(1.139,5.90)]$ were significantly associated with minimum acceptable diet.

Conclusion: The practice of minimum acceptable diet in the study area was inadequate and very low according to notional and world health organization's recommendation. So, strengthening institutional delivery, improving the wealth of the community and exposure to media, and finally empowering women's for education are recommended.

\section{Background}

Sufficient nutrition in the earlier months of life is key to health and growth, and its importance goes throughout life. (1). Later six months breast milk is no longer adequate to meet the nutritional needs of the infant. Therefore, additional foods should be introduced to the child's diet, which is the transition from exclusive breastfeeding to family foods. This is the most critical period for children, because children are most susceptible to malnutrition during this transition. Complementary feeding should be timely, which means that all infants should receive foods in addition to breast milk at age 6 months (2) 
Minimum acceptable diet (MAD) is an indicator for evaluating child feeding practices presented via World Health Organization. It is a combination of the minimum dietary diversity and minimum meal frequency (3). Infant and young children should have a minimum acceptable diet (MAD) to ensure appropriate growth and development, otherwise they are vulnerable to under nutrition especially stunting and micronutrient deficiencies, and increased morbidity and mortality $(1,4)$. In addition to lack of adequate and balanced diet, there are a number of people who are attacked by diseases that occur due to proteinenergy malnutrition and due to lack of disease protecting foods. Children, pregnant women and lactating mothers are most vulnerable by the problem (5).

Although Ethiopia is a manufacturer of a diversity of agricultural products, still the countries is known in the world with the highest number of malnourished population. Malnutrition is primarily seen among the rural residents and the prevalence among children was $48.5 \%$ (6). The Ethiopian government has been try to improve child feeding practices by implementing the national nutrition program of child feeding practices and a multi-sectorial plan of nutrition intervention to end child under nutrition in Ethiopia by 2030 (7). Despite this the progress was not satisfactory, particularly national prevalence of MAD practice was $7 \%$. The problems are higher in rural areas and also significant variation exists between regions. Children in urban areas (19\%) are more likely to feed than those in rural areas $(6 \%)$ and the proportion of children who receive the minimum acceptable diet is highest (27\%) in Addis Ababa and lowest (2\%) in Amara region $(2,8)$.

Even though studies were conducted about the determinants of the optimal complementary feeding practices in Ethiopia, however, insufficient information was documented about minimum acceptable diet practice and its associated factors independently, and most of the data were not representative especially for rural communities. Also, as far as researcher's knowledge concerned, no documented data were accessible specifically in the study area. Therefore, this study was planned to assess minimum acceptable diet practice and its associated factors among children's aged between 6-23 months in rural communities of Goncha district, North West Ethiopia, 2020

\section{Methodology}

\section{Study area and period}

The study was conducted from June 15 to July 152020 in rural communities of Goncha district, which is located in East Gojjam Zone, Amhara region. The full name of this woreda is called as Goncha Siso Enesie, is one of the 21 woredas of East Gojjam zone and located $154 \mathrm{~km}$ East of Bihar Dar, the capital city of Amhara region, and $335 \mathrm{~km}$ far from Northwest of Addis Ababa. Goncha Siso Enesie is boarded on the South by Enarge ena Enawuga, on the West by Hulet Eju Enesie, on the North by Abay River which separates it from North Gonder zone, and on the East by Enebisie sar midir. This woreda is administratively structured by 43 Keble's (41 rural and 2 urban Keble's). Of these rural Keble's 12 are lowlands and 29 are highlands, and major town in the woreda is Gind Weyin. Almost all of the district's population consists of subsistence farmers heavily depending on rains for their agriculture. The district is 
one of the areas in the region, known to experience chronic food insecurity due to variable rainfall pattern, and the population especially who are resided in lowland Keble's are users of government safety net program. In the woreda there are 8 governmental health centers with ratio of one health center to five Keble's and 43 health posts. Due to lack of accessibility to transportation, most of rural community is forced to go longer time with foot to get health care service, and they are exposed to deaths related to treatable diseases. Goncha woreda is inhabited by total populations of 210,423 , of these 108,909 are females and 42,569 are in the reproductive age group (15-49). Out of the total population 28,491 are under five children's and 10,626 (5\% of total population) are infants and young children aged 6-23 months (Goncha woreda health office annual report, 2012 E.C).

\section{Study design}

A community based cross sectional study was employed

\section{Populations}

\section{Source population}

Children's aged 6-23 months with mothers who reside in rural Goncha district

\section{Study population}

Children's aged 6-23 months with mothers who live within selected Keble's

\section{Sampling unit}

Individual child

\section{Eligibility criteria \\ Inclusion criteria}

All children's aged 6-23 months with mothers who are residents of the selected Keble's at least 6 months and available during data collection period were included

\section{Exclusion criteria}

A child's of mothers who were seriously ill during data collection period and children's having acute illness and other conditions which disturb appetite during survey (determined by respondents self-report and by observation) were excluded.

\section{Sample size determination}

The number of sample required for the first objective of this study was calculated using single population proportion formula; by considering the following assumptions: 


$$
\mathrm{ni}=\frac{\left(\mathrm{Z}_{\mathrm{a} / 2}\right)^{2} \mathrm{p}(1-\mathrm{p})}{\mathrm{d}^{2}} \quad \mathrm{ni}=209
$$

By adding 2 design effect and $5 \%$ non-response rate, $N=439$

Where

- $\mathrm{ni}=$ initial sample size required for the study

- $Z$ = standard normal distribution $(Z=1.96)$ with confidence interval of $95 \%$

- $p=8.6 \%$ taken from proportion of MAD in Dembecha district (9) similar study design and nearly similar population

- $d=$ tolerable margin of error $(d)=0.038$

- $\mathrm{N}=$ final sample size

To ensure the adequacy of sample size, Epi info was used to calculate sample size for factors associated with minimum acceptable diet

Finally the maximum sample size was selected from sample size calculated from first objective (proportion of minimum acceptable diet). So, the total sample size required for this study was $=439$

\section{Sampling procedure}

Multi stage sampling technique was used to select the study subjects. First total rural Keble's in Goncha district were stratified in to highland (dega) and lowlands (kola) based on their predominating agroecological characteristics (classification obtained from Goncha woreda health office). Second, from the two strata, 8 from 29 highland Keble's and 4 from 12 lowland Keble's were selected by using lottery method. Then, total sample size was allocated proportionally and sampling interval-"K" was determined.

$\mathrm{K}=\mathrm{N} / \mathrm{n}=1840 / 439=4.19 \sim 4$

Where, $\mathrm{K}=$ sampling interval

$\mathrm{N}=$ total number of 6-23 month age children's in the selected Keble's

$\mathrm{n}=$ total sample size required in this study

Finally, 439 children's aged 6-23 months were selected by using a systematic sampling method based on sampling frame created by Health Extension Worker's (HEW's) record. After randomly identified the first child, we preceded to the second child every 4 interval.

\section{Study variable}

\section{Dependent variable}


Minimum acceptable diet

\section{Independent variable}

Socio demographic characteristics;

Age of mother, marital status, Parent educational status, Parent occupation, Sex of child, Age of child, Birth order of child, Agro ecology

\section{Maternal health related characteristics}

ANC follow up, Place of delivery, PNC follow up

\section{Knowledge of mother on IYCF \\ Child health related characteristics}

Pre lacteal feeding, Time of first breastfeed, Vaccination status, Current child feeding status, Growth monitoring follow up, Time of initiation of complementary food

\section{Household related characteristics}

No of household member, No of under-five child, Household decision making, Exposure to media, Wealth index

\section{Operational definitions/ definition of terms}

\section{Minimum acceptable diet}

proportion of children's aged 6-23 month who had at least minimum meal frequency and minimum diversified diet during the previous day (10)

\section{Minimum meal frequency}

proportion of breast feeding and non-breast feeding children's aged 6-23 months who receive soft, solid and semi-solid foods (but also including milk feeds for non-breast feed child) in the last 24 hours. Breast feed Infants aged 6-8 months 2 times in the last 24 hours; breast feed infants and young children aged 9-23 months 3 times in the last 24 hours. For non-breast feeding infants and young children aged 6-23 months at least 4 times in the last 24 hours (3)

Minimum dietary diversity: proportion of children's aged 6-23 month who receive five or more food groups out of the eight food groups in the last 24 hours. These foods groups used for this indicator are: breast milk, grains, roots and tubers; legumes and nuts; dairy products (milk, yogurt); Flesh foods (meat, fish, poultry and liver/organ meats); eggs; vitamin A-rich fruits and vegetables; and other fruits and vegetables. Quality and quantity of any amount from those groups can be considered as sufficient to count (10) 


\section{Maternal knowledge on IYCF practice}

knowledge of mothers on infant and child feeding practice was measured based on ten knowledge questions. Each correct answer (yes) earned one point, and any wrong answer (no) got zero. The calculated knowledge score ranged from 0 to 10 points. Those who score above the mean $(5.7 \pm 2.6$ standard deviation) was categorized as knowledgeable and those who score below the mean was categorized as not knowledgeable (11)

\section{Exposure to media}

media exposure was categorized as satisfactory or unsatisfactory. Mothers who listen to radio, or watched television at least once a week was satisfactory media exposure, and otherwise unsatisfactory (12)

\section{Data collection tool and procedure}

Primary data was collected using interviewer-administered and structured questionnaire from selected mothers who have had child aged 6-23 months through face to face interview. The data collection tool has six parts; Socio-demographic characteristics, maternal and child health characteristics, maternal knowledge on IYCF practice, twenty four hour recall child feeding practice, household level characteristics and wealth index related characteristics. Twenty four hour recall method for dietary diversity and meal frequency questionnaire was adopted from WHO IYCF indicator assessment tool with some modification to fit with the context (4). the other five parts of the questionnaire were adopted from EDHS (2016) and other related literatures $(11,13) 8$ diploma midwife and nurse professionals for data collection and 21 st degree public health officers as supervisor were participated in the survey.

\section{Data quality control}

Questionnaires were prepared in English and were translated in to local language (Amharic), and again it was translated back in to English to keep its consistency. Data collectors were trained on the aim of the research, content of the questionnaire and how to conduct interview to increase their performance in field activities for one day prior to data collection period. The collected data was checked regularly by supervisors, and principal investigators were followed through phone contact either with supervisor or data collectors for its completeness and consistency. Finally the collected data was cleaned, coded and entered through epidata version 4.0.2.

\section{Data processing and analysis}

Data was entered by using Epi Data entry client version 4.0.2 and exported to SPSS 20 statistical package for analysis. Data cleaning was performed to check for consistencies and values. Dietary diversity score was computed out of eight from eight food groups, and household economic status was measured by constructing wealth index through principal component analysis (PCA) and ranked as low, middle and high wealth index. Descriptive statistics (frequency, mean, standard deviation and Percentage) were used to describe socio-demographic characteristics of the study population. Tables and 
graphs were used for data presentation. Bivariate logistic regression analysis was done to see the association of independent variables on dichotomous outcome variable (MAD, $1=$ met minimum acceptable diet, $0=$ not met minimum acceptable diet). To control the effect of potential confounders and to identify the independent effect of the explanatory variable on minimum acceptable diet, variables with $p$ value less than 0.25 in bivariate logistic regression were considered as candidate for multivariable logistic regression analysis. Before going on multivariable logistic regression analysis multi colliniarity was checked by co linearity diagnostic tests and variables with variance inflation factor (VIF\} less than ten, and variables that fulfill sample size assumptions were entered in to the model. At this level, model fitness was checked with hosmer and lemeshow goodness of fit at $p$ value $\geq 0.05$. Finally, variables with $p$ value less than 0.05 and $95 \% \mathrm{Cl}$ were considered as the predictive for outcome variable. The strength of associations and statistical significances between independent variables and outcome variables were expressed using OR and $95 \%$ of confidence interval respectively.

\section{Result}

\section{Socio-demographic characteristics of study participant}

Among a total of 439 sampled subjects, 430 children's aged between 6 and 23 months with mother were enrolled in the study that makes a response rate of 98\%. Among children's aged 6-23 months, 217 $(50.5 \%)$ were females and 167(38.8\%) were categorized in the age group between 18 and 23 months. The mean age of children was $15.3 \pm 5.4$ (SD) months, and half of children's aged 6-23 months were in the birth order of second to fourth $218(50.7 \%)$. Out of mothers of children aged 6-23 months, majority of $365(84.9 \%)$ mothers were married. With regard to educational status of children's parents, About 283 $(65.8 \%)$ and $262(60.9 \%)$ of mothers and fathers had no formal education respectively. Finally, from total children's parents, about three fourth $320(74.4 \%)$ of fathers were farmers followed by merchants $56(13.0 \%)$, and less than half $182(42.3 \%)$ of mothers were found to be house wife's and about $173(40.2 \%)$ of mothers were farmers (see Table 1 ). 
Table 1

Parental level socio demographic characteristics of children aged 6-23 months, Goncha, Northwest Ethiopia, $2020(n=430)$

\begin{tabular}{|c|c|c|c|}
\hline Characteristics & Category & Frequency(n) & Percentage (\%) \\
\hline \multirow[t]{3}{*}{ Mother age(years) } & $15-24$ & 121 & 28.1 \\
\hline & $25-34$ & 206 & 47.9 \\
\hline & $35-49$ & 103 & 24.0 \\
\hline \multirow[t]{4}{*}{ Marital status } & Married & 365 & 84.9 \\
\hline & Divorced & 28 & 6.5 \\
\hline & Single & 25 & 5.8 \\
\hline & Other ${ }^{\mathrm{a}}$ & 12 & 2.8 \\
\hline \multirow[t]{2}{*}{ Mother education } & No formal education & 283 & 65.8 \\
\hline & Formal education & 147 & 34.2 \\
\hline \multirow[t]{2}{*}{ Father education } & No formal education & 262 & 60.9 \\
\hline & Formal education & 168 & 39.1 \\
\hline \multirow[t]{4}{*}{ Mother Occupation } & Farmer & 173 & 40.2 \\
\hline & House wife & 182 & 42.3 \\
\hline & Merchant & 56 & 13.0 \\
\hline & Other ${ }^{b}$ & 19 & 4.5 \\
\hline \multirow[t]{4}{*}{ Father Occupation } & Farmer & 320 & 74.4 \\
\hline & Merchant & 56 & 13.0 \\
\hline & Employee & 40 & 9.3 \\
\hline & Other ${ }^{c}$ & 14 & 3.3 \\
\hline \multirow[t]{2}{*}{ Sex of a child } & Male & 213 & 49.5 \\
\hline & Female & 217 & 50.5 \\
\hline \multirow[t]{3}{*}{ Age of child in month } & $6-11$ & 123 & 28.6 \\
\hline & $12-17$ & 142 & 33.0 \\
\hline & $18-23$ & 165 & 38.4 \\
\hline Birth order of a child & First & 132 & 30.7 \\
\hline
\end{tabular}




\begin{tabular}{|llll|}
\hline Characteristics & Category & Frequency(n) & Percentage (\%) \\
\hline & Second to fourth & 218 & 50.7 \\
\hline & Above fourth & 80 & 18.6 \\
\hline Agro - ecology & Dega & 230 & 53.5 \\
\hline & Kola & 200 & 46.5 \\
\hline adied/separated, blabor work/no current work/employer, clabor work/no current work \\
\hline
\end{tabular}

\section{Maternal and child health care utilization related characteristics}

During pregnancy of sampled child, less than half $181(42.1 \%)$ of mother attended antenatal care visits four and above times, and about one third $132(30.7 \%)$ of mothers didn't receive antenatal care service. Of the mothers of children aged 6-23 months, more than half 262(60.9\%) of mothers did not utilized postnatal care service, and around two-third, $274(63.7 \%)$ of mothers gave first breast feed for their child after one hour. Out of the total children aged 6-23 months, majority $(60.5 \%)$ of children were delivered at home, and about a quarter $113(26.3 \%)$ of children aged 6-23 months did not start vaccination. Nearly all, $426(99.1 \%)$ of children aged 6-23 months were breast feed at the time of data collection, and around one third, $148(34.4 \%)$ of 6-23 month aged children's were started complementary food after six months. Greater than three fourth, $341(79.3 \%)$ of children did not received monthly growth monitoring and promotion service (see Table 2) 
Table 2

Maternal and child health care related characteristics of children aged 6-23 month, Goncha, Northwest Ethiopia, 2020 ( $n=430)$

\begin{tabular}{|c|c|c|}
\hline Characteristics & Frequency(n) & Percentage (\%) \\
\hline \multicolumn{3}{|l|}{ Antenatal service } \\
\hline Fourth and above visit & 181 & 42.1 \\
\hline One to three visit & 117 & 27.2 \\
\hline No visit & 132 & 30.7 \\
\hline \multicolumn{3}{|l|}{ Place of delivery } \\
\hline Home & 260 & 60.5 \\
\hline Health facility & 170 & 39.5 \\
\hline \multicolumn{3}{|l|}{ Post natal care } \\
\hline Within 7 day & 44 & 10.2 \\
\hline After 7 days & 124 & 28.9 \\
\hline No visit & 262 & 60.9 \\
\hline \multicolumn{3}{|l|}{ Pre lacteal feeding } \\
\hline Yes & 207 & 48.1 \\
\hline No & 223 & 51.9 \\
\hline \multicolumn{3}{|l|}{ Vaccination status } \\
\hline Vaccinated/started & 317 & 73.7 \\
\hline Not started & 113 & 26.3 \\
\hline \multicolumn{3}{|l|}{ first breastfeed for a child } \\
\hline Within 1 hour & 156 & 36.3 \\
\hline After 1 hour & 274 & 63.7 \\
\hline \multicolumn{3}{|l|}{ Current Brest feeding status } \\
\hline Breast feeding & 426 & 99.1 \\
\hline Not breast feeding & 4 & .9 \\
\hline \multicolumn{3}{|c|}{ Time of starting complementary food } \\
\hline Before 6 months after delivery & 87 & 20.2 \\
\hline At 6 months & 147 & 34.2 \\
\hline
\end{tabular}




\begin{tabular}{lll|}
\hline Characteristics & Frequency(n) & Percentage (\%) \\
\hline After 6 months & 148 & 34.4 \\
\hline I do not know & 48 & 11.2 \\
\hline Growth monitoring and promotion service & \\
\hline No & 341 & 79.3 \\
\hline Yes & 89 & 20.7 \\
\hline
\end{tabular}
Mothers Knowledge On child feeding practice and
household level related characteristics

Concerning the knowledge of mothers on infant and young child feeding practice, greater than half, $253(58.8 \%)$ of mothers were knowledgeable. Out of the total study participants, all most one third $138(32.1 \%)$ of children's were living in the houses where family members greater than five. Of the mothers of children aged 6-23 months, two third $284(66 \%)$ of mothers were participated on household decision, and about one third $140(32.6 \%)$ of mothers had satisfactory media exposure (see Table 3 ). 
Table 3

maternal/caregiver knowledge on child feeding and household level related characteristics of children aged 6-23 months, Goncha, Northwest Ethiopia, 2020 $(n=430)$

\begin{tabular}{|c|c|c|}
\hline Characteristics & Frequency(n) & Percentage (\%) \\
\hline \multicolumn{3}{|c|}{ Maternal knowledge on IYCF } \\
\hline Knowledgeable & 253 & 58.8 \\
\hline Not knowledgeable & 177 & 41.2 \\
\hline \multicolumn{3}{|l|}{ Family size } \\
\hline$>5$ & 138 & 32.1 \\
\hline$<=5$ & 292 & 67.9 \\
\hline \multicolumn{3}{|c|}{ No of under five children with in household } \\
\hline Two and above & 150 & 34.9 \\
\hline One & 280 & 65.1 \\
\hline \multicolumn{3}{|l|}{ Media exposure } \\
\hline Unsatisfactory & 290 & 67.4 \\
\hline Satisfactory & 140 & 32.6 \\
\hline \multicolumn{3}{|c|}{ Mother participation on household decision } \\
\hline Mother not involved & 146 & 34.0 \\
\hline Mother involved & 284 & 66.0 \\
\hline \multicolumn{3}{|l|}{ Wealth index } \\
\hline Low & 146 & 34 \\
\hline Middle & 142 & 33 \\
\hline High & 142 & 33 \\
\hline
\end{tabular}

\section{Minimum acceptable diet practice}

From total children's aged 6-23 months, about 54(12.6\%) of children meet the recommended minimum acceptable diet.

\section{Factors influencing minimum acceptable diet practice}

To identify factors associated with minimum acceptable diet practice, bivariate and multivariable logistic regression analysis was done. On binary logistic regression analysis mother education, father education, agro-ecology, family size, place of delivery, postnatal care visit, pre lacteal fed for a child, decision making 
in household, exposure to media, knowledge of mothers on IYCF practice, wealth index, antenatal care visit and time of initiation of complementary food for a child with $p$ value less than 0.25 were considered as candidate for multivariable logistic regression analysis. Before going on multivariable logistic regression analysis, antenatal care visits and time of initiation of complementary food for a child were not fulfilled the sample size assumptions of logistic regression and they were removed, and eleven variables were selected for final analysis. Finally, model fitness was checked by hosmer-lemeshow goodness of fit (which was $p$-value $=0.37$ ) and after that variables with $p$ value less than 0.05 and $95 \% \mathrm{Cl}$ i.e. mother education, place of delivery, exposure to media and wealth index were found to be the potential predictors of meeting minimum acceptable diet.

Accordingly, mothers who had formal education were 2.7 times $[A O R=2.7,95 \% \mathrm{Cl}(1.133,6.231)]$ more likely to provide minimum acceptable diet to their children compared to mothers who had no formal education. The odds of receiving minimum acceptable diet among children's who delivered at health facility were higher compared to children's who delivered at home $[A O R=4.5,95 \% \mathrm{Cl}(1.986,10.362)]$. Also children whose mothers who had been exposed to media had 2.6 times more likely to had minimum acceptable diet $[A O R=2.6,95 \% \mathrm{Cl}(1.303,5.291)]$ than those children's of mother who had not been exposed to media. This study also showed that the odds of providing minimum acceptable diet to their children were 2.5 times more among mothers who have had higher household wealth index [AOR $=2.5$, $95 \% \mathrm{Cl}(1.139,5.90)]$ than those mothers who have had lower household wealth index. (See Table 4) 
Table 4

Bivariate and multivariable logistic regression output showing factors associated with minimum acceptable diet practice among children's aged 6-23 months, Goncha, Northwest Ethiopia, 2020, ( $n$ = 430)

\begin{tabular}{|c|c|c|c|c|c|}
\hline \multirow[t]{2}{*}{ Variable } & \multirow[t]{2}{*}{ Category } & $\begin{array}{l}\text { Not meet } \\
\text { MAD }\end{array}$ & $\begin{array}{l}\text { Meet } \\
\text { MAD }\end{array}$ & \multirow[t]{2}{*}{$\begin{array}{l}\text { COR } \\
(95 \% \mathrm{Cl})\end{array}$} & \multirow[t]{2}{*}{$\begin{array}{l}\text { AOR } \\
(95 \% \mathrm{Cl})\end{array}$} \\
\hline & & $\mathrm{N}(\%)$ & N (\%) & & \\
\hline \multirow[t]{2}{*}{ Agro ecology } & Dega & 196(85.2) & $34(14.8)$ & $\begin{array}{l}1.56(0.867- \\
2.811)\end{array}$ & $\begin{array}{l}0.8(0.374- \\
1.687)\end{array}$ \\
\hline & Kola & $180(90)$ & $20(10)$ & 1 & 1 \\
\hline \multirow[t]{2}{*}{ Place of delivery } & Home & $\begin{array}{l}249 \\
(95.8)\end{array}$ & $11(4.2)$ & 1 & 1 \\
\hline & Health facility & $\begin{array}{l}127 \\
(74.7)\end{array}$ & $\begin{array}{l}43 \\
(25.3)\end{array}$ & $\begin{array}{l}7.6(3.82- \\
15.37)^{\star \star}\end{array}$ & $\begin{array}{l}4.5(1.98- \\
10.36)^{* *}\end{array}$ \\
\hline \multirow[t]{2}{*}{ Pre lacteal fed for a child } & No & $\begin{array}{l}188 \\
(84.3)\end{array}$ & $\begin{array}{l}35 \\
(15.7)\end{array}$ & 1 & 1 \\
\hline & Yes & $\begin{array}{l}188 \\
(90.8)\end{array}$ & $19(9.2)$ & $\begin{array}{l}0.54(0.30- \\
0.983)^{\star}\end{array}$ & $\begin{array}{l}1.28(0.618- \\
2.664)\end{array}$ \\
\hline \multirow[t]{2}{*}{ PNC service } & No & $\begin{array}{l}236 \\
(90.1)\end{array}$ & $26(9.9)$ & 1 & 1 \\
\hline & Yes & $\begin{array}{l}140 \\
(83.3)\end{array}$ & $\begin{array}{l}28 \\
(16.7)\end{array}$ & $\begin{array}{l}1.8(1.023- \\
3.221)^{*}\end{array}$ & $\begin{array}{l}0.7(0.329- \\
1.488)\end{array}$ \\
\hline \multirow[t]{2}{*}{ Mother education } & $\begin{array}{l}\text { No formal } \\
\text { education }\end{array}$ & $\begin{array}{l}268 \\
(94.7)\end{array}$ & $15(5.3)$ & 1 & 1 \\
\hline & $\begin{array}{l}\text { Formal } \\
\text { education }\end{array}$ & $\begin{array}{l}108 \\
(73.5)\end{array}$ & $\begin{array}{l}39 \\
(26.5)\end{array}$ & $\begin{array}{l}6.4(3.41- \\
12.18)^{\star \star}\end{array}$ & $\begin{array}{l}2.7(1.133- \\
6.231)^{*}\end{array}$ \\
\hline \multirow[t]{2}{*}{ Father education } & $\begin{array}{l}\text { No formal } \\
\text { education }\end{array}$ & $\begin{array}{l}245 \\
(93.5)\end{array}$ & $17(6.5)$ & 1 & 1 \\
\hline & $\begin{array}{l}\text { Formal } \\
\text { education }\end{array}$ & $131(78)$ & $37(22)$ & $\begin{array}{l}4.07(2.20- \\
7.50)^{\star \star}\end{array}$ & $\begin{array}{l}1.6(0.71- \\
3.677)\end{array}$ \\
\hline \multirow[t]{2}{*}{ Family size } & $>5$ & $\begin{array}{l}126 \\
(91.3)\end{array}$ & $12(8.7)$ & 1 & 1 \\
\hline & $<=5$ & $\begin{array}{l}250 \\
(85.6)\end{array}$ & $\begin{array}{l}42 \\
(14.4)\end{array}$ & $\begin{array}{l}1.76(0.897- \\
3.469)\end{array}$ & $\begin{array}{l}1.4(0.613- \\
3.098)\end{array}$ \\
\hline \multirow[t]{2}{*}{$\begin{array}{l}\text { Decision making in } \\
\text { household }\end{array}$} & $\begin{array}{l}\text { Mother not } \\
\text { involved }\end{array}$ & $\begin{array}{l}132 \\
(90.4)\end{array}$ & $14(9.6)$ & 1 & 1 \\
\hline & $\begin{array}{l}\text { Mother } \\
\text { involved }\end{array}$ & $\begin{array}{l}244 \\
(85.9)\end{array}$ & $\begin{array}{l}40 \\
(14.1)\end{array}$ & $\begin{array}{l}1.54(0.811- \\
2.944)\end{array}$ & $\begin{array}{l}1.2(0.564- \\
2.528)\end{array}$ \\
\hline
\end{tabular}

Notice * $p$-value $<0.05$, **p-value $<0.01$, COR-crude odds ratio, AOR- adjusted odds ratio, 


\begin{tabular}{|c|c|c|c|c|c|}
\hline \multirow[t]{2}{*}{ Exposure to media } & Unsatisfactory & $\begin{array}{l}270 \\
(93.1)\end{array}$ & $20(6.9)$ & 1 & 1 \\
\hline & Satisfactory & $\begin{array}{l}106 \\
(75.7)\end{array}$ & $\begin{array}{l}34 \\
(24.3)\end{array}$ & $\begin{array}{l}4.3(2.385- \\
7.86)^{\star \star}\end{array}$ & $\begin{array}{l}2.6(1.303- \\
5.29) \star *\end{array}$ \\
\hline \multirow[t]{2}{*}{$\begin{array}{l}\text { Knowledge of mothers on } \\
\text { IYCF practice }\end{array}$} & $\begin{array}{l}\text { Not } \\
\text { knowledgeable }\end{array}$ & $\begin{array}{l}169 \\
(95.5)\end{array}$ & $8(4.5)$ & 1 & 1 \\
\hline & Knowledgeable & $\begin{array}{l}207 \\
(81.8)\end{array}$ & $\begin{array}{l}46 \\
(18.2)\end{array}$ & $\begin{array}{l}4.7(2.157- \\
10.2)^{\star \star}\end{array}$ & $\begin{array}{l}1.6(0.626- \\
3.954)\end{array}$ \\
\hline \multirow[t]{3}{*}{ Wealth index } & Low & $\begin{array}{l}132 \\
(90.4)\end{array}$ & $14(9.6)$ & 1 & 1 \\
\hline & Middle & $\begin{array}{l}130 \\
(91.5)\end{array}$ & $12(8.5)$ & $\begin{array}{l}0.71(0.32- \\
1.61)\end{array}$ & $\begin{array}{l}1.1(0.445- \\
2.72)\end{array}$ \\
\hline & High & $\begin{array}{l}114 \\
(80.3)\end{array}$ & $\begin{array}{l}28 \\
(19.7)\end{array}$ & $\begin{array}{l}2.7(1.193- \\
6.766)^{*}\end{array}$ & $\begin{array}{l}2.5(1.139- \\
5.90)^{*}\end{array}$ \\
\hline
\end{tabular}

\section{Discussion}

The finding of this study revealed that $12.6 \%$ with $95 \% \mathrm{Cl}(9.5,15.7)$ of children's aged $6-23$ months were received the recommended minimum acceptable diet. The result of this study was higher compared to study conducted in Northwest Ethiopia, Dembecha (8.6\%) (9). The variation might be due to difference study period. The above study was conducted in populations were only orthodox religion followers during the fasting season in which feeding habits might be reduced either in food diversity, especially animal source foods or meal frequency which under estimate the finding when compared to other periods. Also the above study was conducted in dry season what we call it "winter" in which nutritional availability of most fruits and vegetables might be low compared to seasons especially "summer" a period in which this study was conducted.

The finding was also higher than EDHS report of 2016, only 7\% of children's aged 6-23 months received minimum acceptable diet (2). The difference might be due to EDHS was done nationwide on a larger sample size. In addition, the EDHS were conducted on culturally different population, which may underrate child feeding practices while this study was conducted on an almost culturally homogenous population with similar feeding practices. The results of this study was higher than studies conducted in Ethiopia multilevel analysis report of EDHS 2016 (6.1\%), Malawi (8.36\%), Nigeria (7.3\%) and Philippines (6.7\%) of children aged $6-23$ months received the recommended minimum acceptable diet $(8,9,14-16)$. The reason for high percentage of feeding practice in this study area might be due to variation in study design, data collection period, and nutrition education with media and health extension workers might play a major role for increasing community awareness towards appropriate child feeding practice (17). 
The result of this study was inconsistent with study conducted in North Shoa (12.5\%) and Northern Ethiopia $(11.9 \%)$ of children's meet MAD $(18,19)$. The finding of this study was lower than study done in wolayita Sodo town (Southern Ethiopia) $21.1 \%$ of children's consumed minimum acceptable diet (20). The variation might be because of difference study settings and study period; this study was conducted in the rural communities where as the above study was conducted in urban communities, as communities from rural area are less likely to feed a minimum acceptable diet than people reside in urban area (2). Also the difference might be due to higher non educated mothers were participated in this study, on the contrary higher numbers of educated participants were included in the above study. Also the study was lower than study done in Bensa District, Sidama region, $16 \%$ of children's consumed minimum acceptable diet (21). The variation might be due to different in sample size and socio demographic characteristics.

This finding was very low compared to national and world health organization recommendations of minimum acceptable diet. This implies that majority of children's resided in the study area might be more vulnerable to under nutrition, especially stunting and micronutrient deficiencies, and that also increased morbidity and mortality (1). The result was also lower than study conducted in different countries; Ghana, Uganda and Kenya in which $29.9 \%, 23.9 \%$ and $48.5 \%$ of children's received recommended minimum acceptable diet, respectively (22-24). Lower finding in this study area might be due to differences in study design, sample size, study period and difference in socio demographic characteristics. Hence, most of the above studies were systemic reviews from demographic health surveys. Also the finding was low compared to 2020 global nutrition report (18.9\%) (25). The variation might be due to difference in sample size and socio demographic characteristics

Mother educational status was significantly associated with minimum acceptable diet. Based on this study, mothers who had formal education were 2.7 times more likely to provide minimum acceptable diets for their children compared to mothers who had no formal education. This finding was supported by a study done in Dembecha (9). This might show that education enables mothers to know the benefits of the practice of child feeding and plays an important role in meeting minimum acceptable diet standards. However, this finding was not supported by the study done in North Shoa, Oromia region and multilevel analysis report of EDHS $2016(8,18)$

This study found that children's born in health facility were 4.5 times more likely to receive minimum acceptable diet than those who born at home. This result was similar with study done in Northwest Ethiopia (9). This might be due to health professional counseling on appropriate child feeding after delivery on health facility increases mothers awareness on practice of minimum acceptable diet; Hence mother's awareness on appropriate child feeding practice who got from health professionals have had a better child feeding practices than their counterparts (17)

This study revealed that children's whose mothers who were exposed to media, i.e. watched television, listen to radio every day or once a week, has 2.6 times more likely to meet minimum acceptable diet than those children's of mothers who watched television and listen to radio less than once a week or not at all. 
This finding was similar to other findings in North Shoa, Oromia region and multi-level analysis report of EDHS $2016(8,18)$. This might be due to the fact that the currently Ethiopian ministry of health and its partners promote child feeding practices through radio, television and family health cards. This might enhance the mother's awareness on feeding a minimum acceptable diet to their children. Also, this might be because of mothers who have been exposed to the media having had better opportunity to access information on appropriate child feeding practices. This could improve the mother's capacity to challenge unfavorable information towards child feeding practices in the community and increase appropriate child feeding habits. On the other hand, this finding was not supported by the study conducted in Dembecha (9)

The present study also revealed the association between household economy and minimum acceptable diet. Children's born from mothers with high wealth index were 2.5 times more likely to receive the recommended minimum acceptable diet than children's born from mothers with low wealth index. This result was nearly similar with study done in the Philippines (26), in which children's born from mothers in the middle wealth index were more likely to meet minimum acceptable diet compared to those children's born from mothers in the poorest wealth index.. The possible explanation of this significance association might be due to the limited food purchasing power to provide diversified diet to their children in peoples with lower wealth index, and also mothers in high wealth index were more likely provide nutritious food to their children compared to mothers from low wealth index households who were more focus on the quantity of food (10). This finding was not supported by other studies conducted in Dembecha, North Shoa and multilevel analysis report of EDHS $2016(8,9,18)$

\section{Conclusion}

Minimum acceptable diet practice among children's aged 6-23 months in the study area was low, almost one from eight children meet the recommended minimum criteria. So, child feeding practices in the study area were not achieved the national and world health organization's infant and young child feeding recommendation. Determinant Factors which significantly affect meeting of minimum acceptable diet were educational status of mother, place of delivery, exposure to media and household wealth index. This implies that the problems are range from individual to household level, and even may go through at large in the community level.

\section{Acronym/abbreviations}

ANC- Antenatal care

AOR-Adjusted Odd Ratio

COR-Crude Odd Ratio

DHS- Demographic Health Survey 
EDHS- Ethiopian Demographic Health Survey

HEW - Health Extension Workers

IYC- Infant and young children

IYCF- Infant and young children feeding

MAD-Minimum Acceptable Diet

MDD-Minimum Dietary Diversity

MMF-Minimum Meal Frequency

PNC-Postnatal care

SPSS- Statistical Package for Social Science

SRS- Systematic Random Sampling

UNICF - United Nations International Children Fund

WHO- World Health Organization

\section{Declarations}

\section{Acknowledgment}

First of all, we would like to thank Hawassa University College of medicine and health science department of Midwifery for giving the chance to conduct this thesis. Also our acknowledgment goes to Goncha woreda health office and health extension workers who are working in selected Keble's, for giving valuable information regarding study area. Our deepest gratitude also goes to data collectors and supervisors for their hard work and commitment during the process of data collection. Last but not least, we would like to thank study participants for their participation and giving their valuable time.

\section{Ethical clearances}

Ethical clearance was obtained from Institutional Review Board of Hawassa University, College of Medicine and Health Sciences with reference № IRB/090/12. Permission letter was obtained from Hawassa University, College of Medicine and Health Sciences, department of midwifery and submitted to Goncha woreda administration and health offices. Then, Goncha woreda administrative bodies were communicated and permission was obtained. Finally, after explaining the aims of the research and contents of the document informed consent was taken from the mothers. To keep the privacy of clients, their names were not included in the check list and identification of the client was only possible through numerical codes. All methods were performed in accordance with the institutional guidelines. 


\section{Consent for publication}

Not applicable

\section{Availability of data and materials}

The datasets used during the current study are available from corresponding authors when reasonably desired.

\section{Competing interests}

The authors declared that no competing interests exist

\section{Funding}

Hawassa University

\section{Authors' contributions}

Conceptualization: BB. Development and design of methodology: BB AK EK. Entering data into computer software: BB. Formal analysis: BB AK EK. Supervision: BB AK EK. Writing original draft: BB editing: AK EK. All authors read and approved the final manuscript.

\section{References}

1. Das Jai K, Salam Rehana A, Imdad Aamer, A BZ. Infant and young child growth. Reproductive, Maternal, Newborn, and Child Health. 2015:225.

2. EDHS E. demographic and health survey 2016: key indicators report. The DHS Program ICF. 2016.

3. WHO, UNICEF, USAID. Indicators for assessing infant and young child feeding practices: part 1: definitions: conclusions of a consensus meeting held 6-8 November 2007 in Washington DC, USA. 2008.

4. WHO, UNICEF, USAID. Indicators for assessing infant and young child feeding practices part 2: measurement. The World Health Organization Geneva; 2010.

5. Ababa A. Federal democratic republic of Ethiopia ministry of health. Ethiopia: Postnatal Care. 2003.

6. Endris Neima, Asefa Henok, Dube Lamessa. Prevalence of malnutrition and associated factors among children in rural Ethiopia. BioMed research international. 2017;2017.

7. Siba Eyerusalem, Biruk T. ENDING RURAL HUNGER. 2017.

8. Aberash Tassew Abay, Tekle Dejen Yemane, Belachew Abate Bekele, Meressa AB. Factors affecting feeding 6-23 months age children according to minimum acceptable diet in Ethiopia: A multilevel analysis of the Ethiopian Demographic Health Survey. PloS one. 2019;14(2).

9. Mulat Efram, Alem Girma, Woyraw Wubetu, Habtamu T. Uptake of minimum acceptable diet among children aged 6-23 months in orthodox religion followers during fasting season in rural area, 
DEMBECHA, north West Ethiopia. BMC Nutrition. 2019;5(1):18.

10. WHO Global Nutritional Monitoring F. operational guidance for tracking progress in meeting targets for 2025. Switzerland: World Health Organisation. 2017.

11. Dagmawit Solomon, Aderaw Zewdie, Kassaw TT. Minimum dietary diversity and associated factors among children aged 6-23 months in Addis Ababa, Ethiopia. International journal for equity in health. 2017;16(1):181.

12. Melkamu Beyene, Abebaw Gebeyehu Worku, Mesele MW. Dietary diversity, meal frequency and associated factors among infant and young children in Northwest Ethiopia: a cross-sectional study. BMC public health. 2015;15(1):1007.

13. Dangura Dalecha, Samson G. Dietary diversity and associated factors among children 6-23 months of age in Gorche district, Southern Ethiopia: Cross-sectional study. BMC pediatrics. 2017;17(1):6.

14. Guirindola Mildred O, Maniego Ma Lynell V, Silvestre Catherine J, S ACC. Determinants of Meeting the Minimum Acceptable Diet Among Filipino Children Aged 6-23 Months. Philippine Journal of Science. 2018;147(1):75-89.

15. Nkoka Owen, Mhone Thomas G, AM NP. Factors associated with complementary feeding practices among children aged 6-23 mo in Malawi: an analysis of the Demographic and Health Survey 20152016. International health. 2018;10(6):466-79.

16. Udoh Ekerette Emmanuel, Olukemi A. Complementary feeding practices among mothers and nutritional status of infants in Akpabuyo Area, Cross River State Nigeria. SpringerPlus. 2016;5(1):2073.

17. Zeweter Abebe, Gulelat DesseHaki, Kaleab B. Health extension workers' knowledge and knowledgesharing effectiveness of optimal infant and young child feeding are associated with mothers' knowledge and child stunting in Rural Ethiopia. Food and nutrition bulletin. 2016;37(3):353-63.

18. Gizaw Getu, Tesfaye Gudina. Minimum Acceptable Diet and Factor Associated with It Among Infant and Young Children Age 6-23 Months in North Shoa, Oromia Region, Ethiopia. 2019.

19. Mekbib Ergib, Shumey Ashenafi, Ferede Semaw, Fisaha H. Magnitude and factors associated with appropriate complementary feeding among mothers having children 6-23 months-of-age in northern Ethiopia; a community-based cross-sectional study. J Food Nutr Sci. 2014;2(2):36.

20. Mekonnen Tefera Chane, Workie Shimelash Bitew, Tesfa MekonenYimer, Fekadu MW. Meal frequency and dietary diversity feeding practices among children 6-23 months of age in Wolaita Sodo town, Southern Ethiopia. Journal of Health, Population and Nutrition. 2017;36(1):18.

21. Muntasha Birhanu, Teferi Abegaz, Fikre R. Magnitude and Factors Associated with Optimal Complementary

22. Feeding Practices among Children Aged 6-23 Months in Bensa

23. District, Sidama Zone, South Ethiopia. Ethiop J Health Sci 2019;29(2).

24. Issaka Abukari I, Agho Kingsley E, Burns Penelope, Page Andrew, Dibley Michael J. Determinants of inadequate complementary feeding practices among children aged 6-23 months in Ghana. Public 
health nutrition. 2015;18(4):669-78.

25. Mokori Alex, Schonfeldt Hettie, L HS. Child factors associated with complementary feeding practices in Uganda. South African Journal of Clinical Nutrition. 2017;30(1):7-14.

26. Macharia Jacqueline, Mbithe Dorcus, Harun K. Feeding Practices and Nutrition Status among Children Aged 6-23 Months after Discharge from Supplementary Feeding Program in Isiolo County, Kenya. Food Sci Nutr Res. 2019;2(2):1-6.

27. Micha R, Mannar V, Afshin A, Allemandi L, Baker P, Battersby J, et al. 2020 Global nutrition report: action on equity to end malnutrition. 2020.

28. Abdurahman, Eshetu E, H M. Magnitude and determinants of complementary feeding practices in Ethiopia: A systematic review and meta-analysis. Heliyon. 2019;5(7). 